Supporting Information

\title{
Enzyme Catalyzed Hydrogel as Versatile Bioadhesive for Tissue Wound Hemostasis, Bonding and Continuous Repair
} Juan Zhou ${ }^{\mathrm{a}}$, Yanzhe $\mathrm{Wu}^{\mathrm{a}}$, Xihe Zhang ${ }^{\mathrm{a}}$, Jiahui Lai ${ }^{\mathrm{a}}$, Yuanli Li ${ }^{\mathrm{a}}$, Jian Xinga ${ }^{\mathrm{a}}$, Liping Teng $^{\mathrm{b}, *}$ and Jinghua Chen ${ }^{\mathrm{a}, *}$

a Key Laboratory of Carbohydrate Chemistry and Biotechnology, Ministry of Education, School of Pharmaceutical Science, Jiangnan University, Wuxi 214122, China

b Wuxi School of Medicine, Jiangnan University, Wuxi 214122, China.

E-mail: tengliping@jiangnan.edu.cn; chenjinghua@jiangnan.edu.cn.

\section{Synthesis of tannic modified gelatin (Gel-TA) ${ }^{1}$}

Gelatin $(1 \mathrm{~g})$ was suspended in deionized water $(100 \mathrm{~mL})$ and stirred at $60^{\circ} \mathrm{C}$ for $2 \mathrm{~h}$ to form a gelatin solution. Then, $\mathrm{NaOH}$ solution $(12 \mathrm{M})$ was added into the solution drop by drop to adjust $\mathrm{pH}$ to 8.5. Next, TA was dissolved in deionized water and the resulting solution was slowly added to the gelatin solution at defined ratio $\left(3.4 \%\right.$, w/w to gelatin). The mixture was stirred for $3 \mathrm{~h}$ at $60{ }^{\circ} \mathrm{C}$ accompanied by bubbling air. In this process, the $\mathrm{pH}$ was maintained at 8.5 by dropwise addition of $\mathrm{NaOH}(1 \mathrm{M})$. After that, the reaction was adjusted to $\mathrm{pH}$ 7.4 , and dialyzed in the flowing deionized water for $2 \mathrm{~d}$ at r.t. $\left(\mathrm{MW}_{\text {cut-off }}=3500\right.$ Da). The pure product was obtained by lyophilization.

\section{Characterization of GTT hydrogels}


The FT-IR spectra of Gel, TA and freeze-dried GTT hydrogels (GTT-1, GTT-2, GTT-3) were recorded on Bruker Tensor II instrument with the frequency range of 4000-400 $\mathrm{cm}^{-1}$. The ${ }^{1} \mathrm{H}-\mathrm{NMR}$ spectra of Gel, TA and GTT hydrogels were measured using Bruker Aduance III $400 \mathrm{MHz}$ NMR instrument. $\mathrm{D}_{2} \mathrm{O}$ was used as the solvent and internal standard. The cross-section morphology of GTT hydrogels were observed by scanning electron microscopy (JSM-5510LV).

A

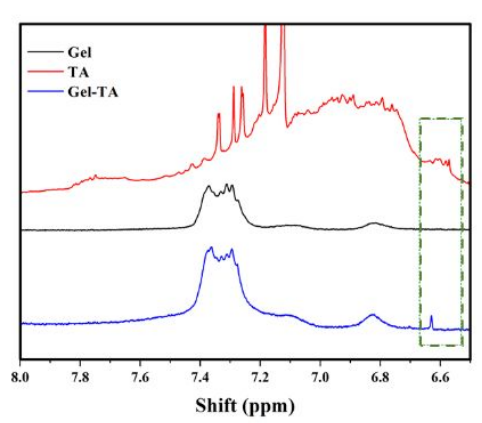

B

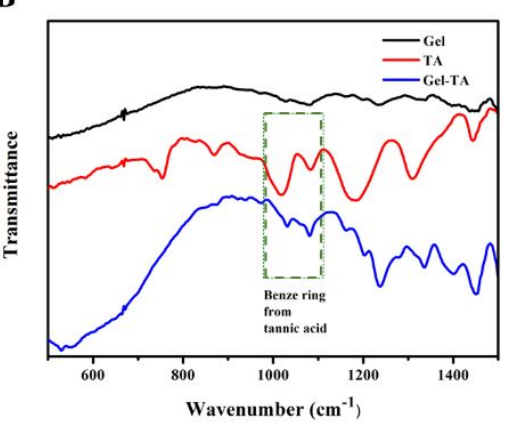

Fig. S1 The enlarge images of NMR and FTIR results of Gel, TA and Gel-TA.

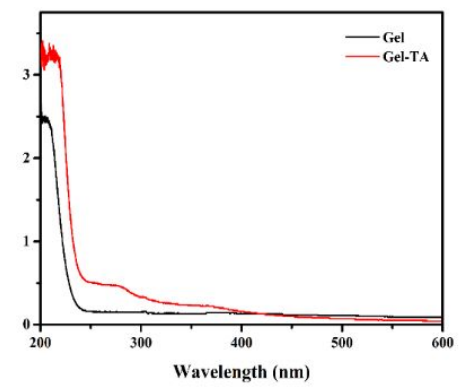

Fig. S2 UV absorbance of gelatin and Gel-TA.
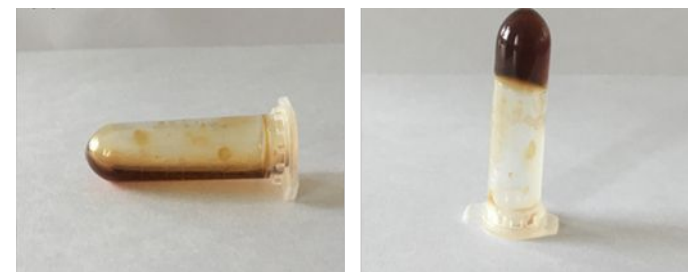

Fig. S3 Optical images of GTT hydrogels formation. 

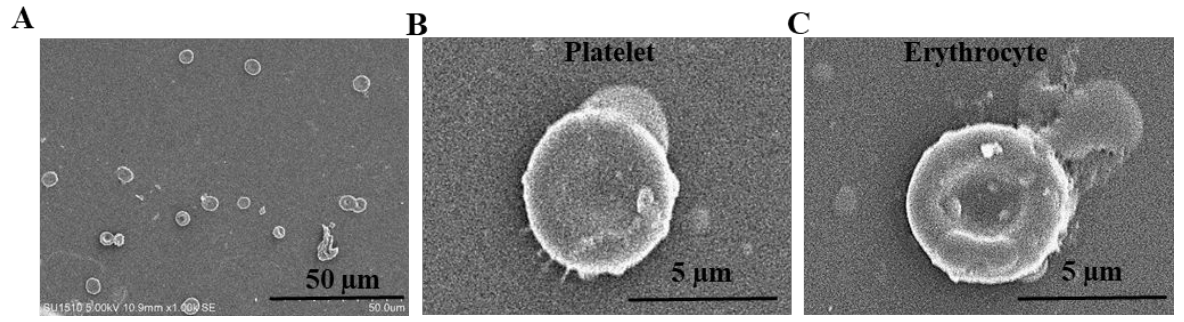

Fig. S4 (A) SEM images of interfacial interaction between whole blood and GTT-3 hydrogel. Enlarge SEM images of activation behavior of (B) platelet and (C) erythrocyte on GTT-3 hydrogel.

TNF- $\alpha$

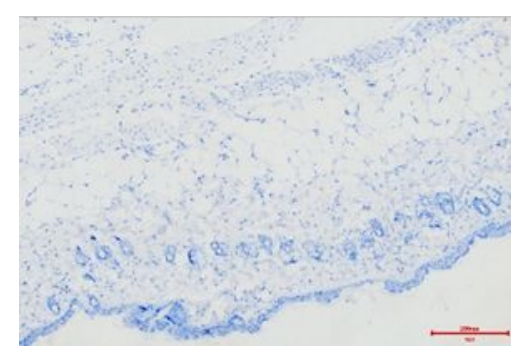

CD206

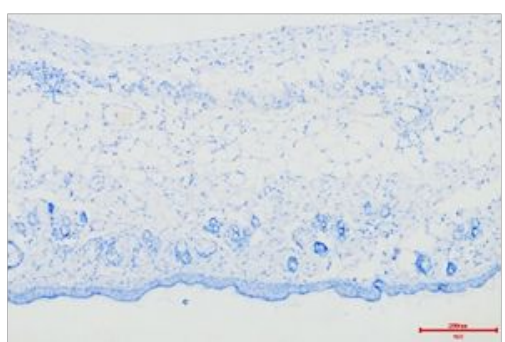

VEGF

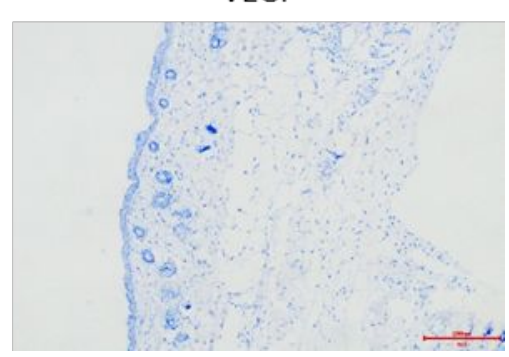

Fig. S5 Negative controls for immunohistochemical analysis

\section{References:}

(1) Guo, J.; Sun, W.; Kim, J. P.; Lu, X.; Li, Q.; Lin, M.; Mrowczynski, O.; Rizk, E. B.; Cheng, J.; Qian, G.; Yang, J. Development of tannin-inspired antimicrobial bioadhesives. Acta Biomater. 2018, $72,35-44$. 